\title{
Ekaterina Ivanova and Michaela Neumayr* The Multi-Functionality of Professional and Business Associations in a Transitional Context: Empirical Evidence from Russia
}

DOI 10.1515/npf-2016-0011

\begin{abstract}
In the literature it is generally assumed that activities of voluntary membership based associations operating in stable institutional environments are multi-faceted, contributing simultaneously to societal, economic and political spheres. This article, drawing on the concept of functions of non-profit organizations investigates, whether the multi-functional character of associations holds true in the context of transitional Russia. The paper examines the relative importance of the advocacy, community building and service delivery functions, fulfilled by different types of associations. The original empirical data from exploratory interviews with 15 leading experts on associational activities was triangulated by a confirmatory survey of 215 associations across Russia. The results confirm that the absolute majority of the examined associations are multifunctional. Advocacy is considered to be the most important function for all types of associations. The findings suggest that business associations and intermediary unions are more active in policy advocacy directed toward the government, while liberal professional societies are more engaged in public advocacy addressing society at large. This study highlights importance of domestic associations for countries in transition as an institutional infrastructure of organized civil society, democratic development and market economy.
\end{abstract}

Keywords: multi-functionality, associations, institutional infrastructure, Russia

\footnotetext{
*Corresponding author: Michaela Neumayr, Institute for Nonprofit Management, WU Vienna University of Economics and Business, Welthandelsplatz 1, Vienna, 1020, Austria, E-mail: michaela.neumayr@wu.ac.at

Ekaterina Ivanova, Institute for Nonprofit Management, WU Vienna University of Economics and Business, Welthandelsplatz 1, Vienna, 1020, Austria,

E-mail: dr.ekaterina.ivanova@gmail.com
} 


\section{Introduction: Societal Functions of Nonprofit Organizations}

Over the last two decades, nonprofit organizations (NPOs ${ }^{1}$ ) in transitional countries have been given credit for contributing to the provision of important social services, as well as for serving as an institutional infrastructure of civil society (Wagner 2012). In these countries, NPOs not only became more visible, as their growth rates indicate, but also sought to challenge the monopoly of the state in the societal sphere. The focus of this paper is on professional and business associations (PBAs), which represent a particular type of nonprofit organizations that operate on a voluntary mutual benefit membership basis. A central feature of nonprofit associations lays in their complex nature. As Tschirhart points out, the ambivalence of associations is reflected in the fact "that they support democratic processes, give voice to special interests, regulate behaviors, develop and diffuse innovations, and provide psychological and social rewards... also support inequalities, repress voices, and constrain freedoms" (2006, 526). It is argued that in the context of transitional countries, where institutions of civil society, democratic governance and market infrastructure are not fully developed to fit the new post-communism reality, associations are filling such institutional voids (Yakovlev etal. 2010). They do so in a variety of ways, by contributing to the creation of societal structures, establishing representational channels, fostering social capital and creating powerful professional networks. Russian PBAs account for $14 \%$ of employment in the nonprofit sector, according to Mersiyanova's (2010) estimates. PBAs compose the fourth largest group in the domestic nonprofit sector, meaning that they play a recognizable role as an employer. With regard to studies on PBAs in Russia, only a few scholars consistently examined this complex phenomenon of associations. The prevailing perspectives that they used stem from sociology of professions (Mersiyanova, Cheshkova, and Krasnopolskaya 2011; Moskovskaya et al. 2013), political theories of institutional channels of representation (Duvanova 2011) and economic theory of collective action (Pyle 2006; Yakovlev et al. 2010). Given a persisting lack of an overarching interdisciplinary theory of associations, prevailing theoretical immaturity and fragmentation of this field of studies, as well as a need for more empirical studies on associations (Tschirhart 2006; Haynes and Gazley

1 In this paper in order to be consistent we name organizations that constitute nonprofit sectors as NPOs, avoiding other options, such as non-governmental organizations or civil society organizations. 
2011), the present study addresses this call by applying a nonprofit research paradigm.

Empirical investigations of the nonprofit sector's societal roles across different countries show that the functions that nonprofit organizations perform notably differ, varying against the non-profit regimes in which they are embedded (Salamon, Sokolowski, and Anheier 2000). Similar to any nonprofit organization operating in a pluralistic democratic society, associations in transitional context are expected to perform a certain set of functions. The existing strand of the non-profit literature provides a variety of different approaches to classifying functions of nonpofit organizations (Warren 2001; Salamon, Hems, and Chinnock 2000; Frumkin 2005; Neumayr et al. 2009). The purpose of this paper is to examine empirically, whether the multifunctional nature of associations (Zimmer 2007) holds true for different types of associations operating in a country transitioning to democracy, market economy and civil society (Yakovlev et al. 2010). Therefore we refer to an integrated theoretical framework of functions of NPOs that distinguishes between service delivery, advocacy and community building functions (Neumayr etal. 2009) and apply it on the organizational micro-level. This theoretical framework allows us to use an analytical toolbox of multiple functions simultaneously performed by a single association.

In doing so, this article seeks to enhance our understanding of societal roles of associations by discussing the functions that different types of PBAs fulfil in a particular transitional country. It begins with an overview of the integrative framework of NPOs' functions. The article then focuses on the mixed-methods empirical investigation of the functions of PBAs in Russia and compares the relative importance of these functions between different types of PBAs. Using a unique compositional dataset, the article further contextualises PBAs' activities. The conclusion reflects on the contribution of PBAs to a domestic institutional infrastructure that shapes emerging capitalism, democracy development and organized civil society in Russia.

\section{Theoretical Framework: PBAs' Roles and their Importance for a Transitional Context}

The seminal work by the Johns Hopkins Comparative Nonprofit Sector (JHCNPS) Project enhanced our understanding of the different roles of NPOs and was convincing in showing how differently nonprofit sectors are structured in various settings around the world (Salamon et al. 2013). Since Russia was not 
involved in the JHCNPS Project, we can only assume that it similar to most of the examined transitional Central and Eastern European countries, takes a borderline position between two types of nonprofit regimes (Salamon, Sokolowski, and Anheier 2000). A further confirmation to this was given by Ljubownikow (2011, 11), who claimed that "contemporary Russian civil society embeds within itself aspects of both statist and liberal facets of civil society arrangements". Given that NPOs play a wide range of societal roles, contributing simultaneously to economic, political and social domains, multi-tasking and multi-functionalism refer to their most distinctive characteristics (Edwards and Foley 2001; Zimmer and Freise 2008). Since nonprofit studies cut across the confines of a single discipline, there are a number of difficulties that researchers face examining functions performed by NPOs.

Firstly, due to a lack of common understanding of the term 'function', the task of comparative empirical analysis of nonprofit's functions, as Neumayr et al. (2009) pointed out, becomes quite challenging. The only available definition of NPOs' functions to our knowledge has been given by Anheier $(2005,174)$, which says that "by function we mean the normal tasks or roles that nonprofit organizations can be expected to perform". Secondly, there are few attempts in the literature to systematically examine and compare the nonprofit's societal functions in different nonprofit regimes. At least two approaches to defining the functions of NPOs stand out. The first one adopts a rather narrow single perspective, such as that of foundations (Prewitt 1999), or unfolds within a particular national context, predominantly that of the USA (Land 2001; Frumkin 2005). Adherents of the second approach employ multiple perspectives, such as in the case of democratization and peace-building (Paffenholz and Spurk 2006), or place their studies in cross-national settings (Salamon, Hems, and Chinnock 2000; Neumayr et al. 2009), thus enabling comparative analysis. Finally, based on different identified functions that NPOs fulfill, Neumayr et al. (2009) came to the conclusion that among the roles assigned to NPOs, the most prominent one belongs to the service delivery function, followed by the advocacy and community building functions. It is clear that the extent, to which NPOs fulfill any one of the identified functions, as well as the composition of the functions performed simultaneously, will vary depending on the national context or type of NPO.

For the present study we prefer the micro-oriented framework of nonprofits' societal functions (Neumayr et al. 2009), instead of the macro-oriented mainstream approach of the JHCNPS Project (Salamon, Sokolowski, and Anheier 2000). The choice is based on a critique of the latter, since in defining nonprofit regimes it does not focus on the composition of different societal functions performed simultaneously by an individual NPO. In the prevailing macro- 
approach NPOs are assigned either to a group of service providing, advocacy/ expressive oriented or hybrid nonprofit organizations (Minkoff 2002). The theoretical framework used in the present study provides more nuanced information on a spectrum of nonprofits' societal functions, rather than assigning the whole non-profit sector of a country to a single dominant function out of only two possible options (service or expressive), as it has been done in the JHCNPS Project. We assume that applying the integrative framework of the nonprofit functions developed by Neumayr et al. (2009) best suits our purpose. Such a choice is justified by the fact that the featured study had been designed against a theoretically based integrative framework and had been empirically tested in the Austrian-Czech comparative research project against two welfare-state regimes, representing stable (Austria as a developed country) and unstable (the Czech Republic as a country in transition) institutional environments.

\section{Theoretical Model: Integrative Framework of Nonprofit Organizations' Functions}

The theoretical framework used for this study for measuring nonprofit organizations' functions comprises three clearly defined functions, namely service delivery, advocacy, and community building. This integrative framework implies that any communication, decision or action carried out by various types of nonprofit organizations could be assigned to any of the main functions - service delivery, community building and advocacy, which contributes to one, two or all three functional subsystems of society (Neumayr 2010). To better illustrate this, the concept is displayed in a triangle shape with nonprofits' three main functions located at its corners (see Figure 1).

The functions are further connected to three corresponding subsystems of society - the economic, the political and the communitarian (Neumayr et al. 2009). The service-delivery function serves the economic subsystem of society. Nonprofit organizations are most typically associated with rendering services to their beneficiaries against fixed prices and administer payments for these services. The distinctive characteristic of services provided by NPOs is that they belong to the quasi-public goods, contributing to the satisfaction of individual needs and to the common good (Neumayr and Meyer 2010, 6).

The advocacy function serves the political subsystem of society. By participating in the political process, NPOs are directly involved in decision-making surrounding collectively binding decisions and policies. NPOs reflect the pluralistic nature of a modern society by giving voice to various points of view and 


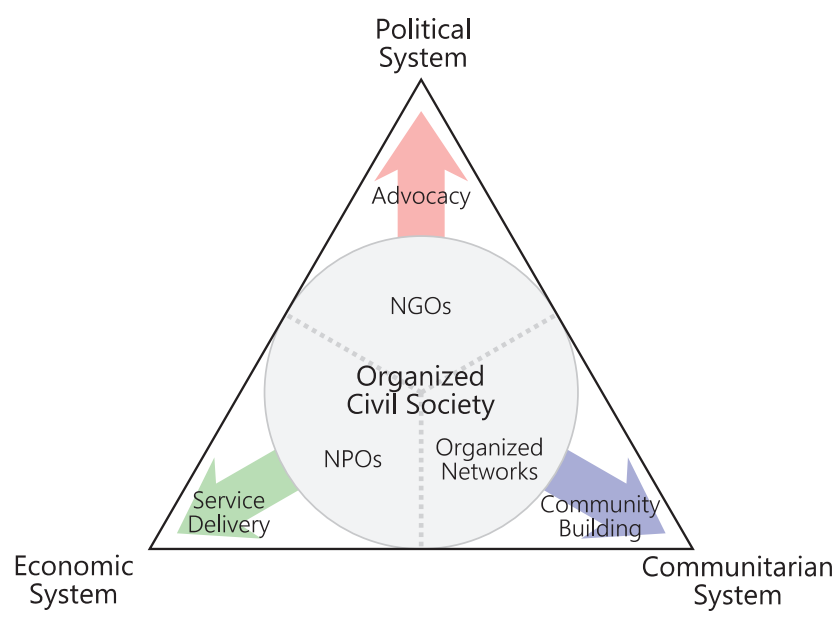

Figure 1: The conceptual framework of nonprofits' functions as contributions to societal subsystems.

Note: Modified from Neumayr et al. (2009) and Then and Kehl (2011).

diverse groups of interests, stimulating public discussion, and pushing governments for action on matters of public interest. There are at least two major directions - policy and public - in which NPOs exercise advocacy (Knapp, Robertson, and Thomason 1990). Through policy advocacy, NPOs can be directly involved in drafting legislation as experts or lobbyists, depending on the legal restrictions in different countries. Alternatively, by public advocacy, NPOs can be active indirectly through public relation campaigns aimed at articulating certain societal problems, raising public awareness, and pressing for adequate solutions.

The third function of NPOs, the community building function, is tied to the communitarian subsystem of society. This function is executed by NPOs through interaction at the interpersonal and interorganizational levels by enacting and solidifying relationships. This interaction is in turn conducive to the enhancement of both bonding and bridging social capital (Putnam 2000, 1993; Anheier 2005). NPOs' activities under the community building function result in a sense of belonging to a group that unites individuals around certain professional, business or recreational interests. In other words, the socializing effects of associating are of crucial importance for promoting collective action for the common good.

In other words, it is assumed.

In Figure 1 each function is coupled with the corresponding societal subfield following Luhmann's (1984) systems theory. This gives us a rough visual 
representation of the nonprofit sector's functional capacity to serve as the institutional infrastructure for democracy, capitalism and an organized civil society. Moreover, due to the common discursive practices and semantic similarities, the types of organizations representing organized civil society are connected to the corresponding functions by arrows. The underlying assumption of this concept is that NPOs are multifunctional (Edwards and Foley 2001; Zimmer and Freise 2008; Zimmer 2007) and contribute simultaneously to up to three different functional subsystems but to varying degrees (Neumayr et al. 2009).

In this paper we apply the integrative framework of nonprofit functions to professional and business associations, which represent a specific type of NPOs, according to international taxonomy of nonprofits (Anheier 2005). We assume that associations, similar to any other NPO, perform three central functions service delivery, advocacy and community building. Examples of service delivery activities performed by associations are information and consulting services for members on the current topics. Associations conduct advocacy by influencing legislature in accordance with the collective interests of their members. Community building by associations takes place when members are provided opportunities for networking at events, contributing to building trust among each other. We admit that there might be a certain degree of overlapping and convergence between the functions in the context of associational activities. For example, events for members are both a service, since they serve to provide information, but at the same time participation in events encourages networking among members and thus contributes to community building. Nevertheless, according to the theoretical framework of a triangle each activity can be assigned to a corresponding function that it serves in the first place. Thus, we assume that the multi-method operationalization of functions for the undertaken empirical investigation, in which we strictly followed the conceptual framework and definitions of functions, stated above, allowed us to correctly distinguish between the functions that associations perform.

\section{Data and Methods}

A mixed-method research design, using both qualitative and quantitativemethodologies, was employed for this study. ${ }^{2}$ The collection of exploratory data from expert interviews took place in September 2011 prior to the

2 Since empirical data used in this paper arise from a larger research project further details about the research design can be found in Ivanova (2015). 
confirmatory survey. The aim of the interviews was to collect rich empirical data on the activities of the Russian PBAs in order to learn more about the ways, tactics and strategies they employ to fulfill the service delivery, the advocacy and the community building functions. Thereby we examined whether the integrative framework of nonprofits' functions is applicable in the context of Russia's transitional society. In total, 15 one-to-one semi-structured expert interviews, supported by an interview guide, were carried out. All interviews were fully transcribed and analysed using qualitative content analysis (Mayring 2010; Krippendorff 2004). The questions guiding the expert interviews referred to three thematic sections. In the first section we asked the experts about the success stories and particular organizational characteristics of PBAs in comparison to other NPOs. The second section of questions focused more on the functions of PBAs and their relationships with the public sector. The third section addressed the factors influencing PBAs' mission. Thus, evidence from the interviews on the key directions of PBAs' activities, their goals and successes allowed us to gain a better understanding of the way the functions are performed in a transitional context.

The quantitative part of this study is based on survey data that were collected between December 2012 and February 2013. The survey addressed top executives of PBAs and aimed to identify the composition of the functions that PBAs perform and their relative importance for the organization. The questionnaire used was adopted from Neumayr et al. (2009), in order to make it applicable to the specific features of PBAs. While in the first part of the questionnaire organizational data like age, governance structure, type of association, territorial span, number of employees, fields of activity, basis and type of membership, and number of members and volunteers were requested, the second part covered organizational activities. Its key questions referring to the functions of NPOs strongly correspond to Neumayr' study (2009), but were extended by a question on the character of organizational activities in relation to the existing societal structures. The invitations to take part in the survey were personalized and distributed by means of email only. A total of 215 highest level staff members (primarily executive directors) provided valid survey responses (response rate: $11 \%, 215$ of 2,000).

\section{Sample}

For the expert interviews we drew a sample of 15 informants, relying on a network of personal contacts, which enabled us to secure access to high-profile 
knowledgeable practitioners occupied in the field of PBAs. Due to general difficulties with access to informants in Russia, the applied sampling approach was the only possible alternative. Moscow was chosen as a sampling point, since PBAs traditionally have their head offices in the capital. The interviewees were selected on the basis of the multi-stakeholder representation criterion, field of activity and geographical focus. The interviewees represented four different stakeholders, including four executives of PBAs, five members of PBAs, four established researchers focusing on PBAs, and two government relations consultants with extensive experience in the field of PBAs. The spectrum of organizational activities that experts represented varied from business associations in the extractive, production and services sectors of the economy, professional associations of managers, scientists and educators to inter-sector peak associations for entrepreneurs and industrialists. Most of the PBAs in which experts are engaged are active on a nationwide scale with headquarters in Moscow. Such an approach to selection of the key informants that were actively involved in PBAs' activities guarantees a diverse sample, representing internal and external perspectives on the activities of PBAs, and enabled us to construct a balanced picture of the phenomenon under study.

For the survey of executives of PBAs, a purposive sample of 2,000 organizations was designed to be representative of the operating PBAs through all federal districts of Russia. Due to technical problems associated with the diverse forms of PBAs' incorporation, it was impossible to generate a list of such organizations on the basis of the national register of all NPOs, which is administered by the Ministry of Justice of the Russian Federation. For this reason we decided to choose the list approach (Grønbjerg, Liu, and Pollak 2010) for the construction of a sample database, because it was easy to obtain the available lists of the existing PBAs. To implement the list approach, we developed a single database from multiple sources that already included lists of the targeted organizations. The major sources that we used included the lists of the central and regional offices of the peak PBAs from the official registry of the Russian Ministry of Justice, as well as the registries of the specialized online-resources devoted to activities of NPOs in Russia. In order to be included in the sample, an NPO had to correspond to two selection criteria: being a membership based organization and being engaged in representing professional or business related fields of activities. Thus, a combination of modal instance and heterogeneous sampling approaches was considered as the best possible alternative, when parameters of the Russian population of PBAs are unknown. By combining these opposite methods, we tried to capture both the most typical organizations, as well as to identify the broad spectrum of PBAs. We cannot claim that we have achieved a representative sample of the responding PBAs in relation to the 
initial sample. It appears that the more publicly visible associations were more likely to participate in the survey. Nevertheless, we assume that the organizations that took part in the survey provide a quite exhaustive picture of the organizational ecology of PBAs across the country.

\section{Quantitative Measures for PBAs' Functions}

In order to get a comprehensive picture of the composition of functions that PBAs fulfil - service, advocacy and community building, two separate approaches to measuring PBAs functions were applied (compare Neumayr et al. (2009). For the first approach, respondents were asked to evaluate their activities in terms of goals. The question therefore consisted of three statements about organizational goals, listed in Table 1. Respondents were asked to indicate the importance of the individual statements by allocating a total of 100 points between the three statements, giving more points to higher priorities. An overall score for each of the three functions was calculated as a mean value of the sum of the corresponding individual values for each function.

Table 1: The functions of PBAs, measured in organizational goals.

\begin{tabular}{|c|c|c|}
\hline \multirow{4}{*}{$\begin{array}{l}\text { We are representing our member's interests. } \\
\text { We are providing services. } \\
\text { We are bringing people together. }\end{array}$} & & $\%$ \\
\hline & & $\%$ \\
\hline & & $\%$ \\
\hline & 100 & $\%$ \\
\hline
\end{tabular}

Source: Russian PBA-Survey, 2013

For the second approach, respondents were asked to indicate the percentage of the overall hours worked within the organization by paid employees for particular activities. The given fields of activities are displayed in Table 2. Though other scholars have included unpaid work by volunteers, we refer to paid work only, since this approach was more appropriate with regards to PBAs in a transitional country. In order to calculate the share of paid work hours on advocacy, we added the values of the first two categories 'Policy Advocacy' and 'Public Advocacy' and calculated their mean value. The share of work time devoted to 'administration' was excluded from further analysis, so as to insure the full comparability of findings in relation to the three major functions. In order to calculate the relative importance of each function, we calculated the amount of the work time devoted to a function, measured as the share of all work time for the total of the three functions (compare Neumayr et al. 2009). 
Table 2: The functions of PBAs, measured in work time.

Policy Advocacy: supporting democratic processes by contributing to the passage of $\%$ legislation, serving as intermediaries between the state and individual members

Public Advocacy: promoting an agenda by influencing the public opinion

Service delivery to members and society at large: providing specialized information $\quad \%$ and analytical data, developing and diffusing innovations

Community building: conducting events, making professional rankings, providing social and psychological rewards, regulating behavior through codes of ethics and professional standards

Administration: planning, fundraising, accounting, HR management, reporting Other:

$\begin{array}{r}\% \\ \% \\ 100 \% \\ \hline\end{array}$

Source: Russian PBA-Survey, 2013

\section{Analysis}

In the exploratory part of the study, expert interviews on the aims, activities and success stories of PBAs were analysed in order to figure out the tactics and strategies for fulfilling their societal functions in Russia. For this purpose we conducted a qualitative content analysis (Krippendorff 2004; Mayring 2010) using Atlas.ti software. The findings from the qualitative data supported the applicability of the integrative conceptual framework of nonprofits' functions. In the quantitative part of the study, we used this conceptual framework to measure the relative importance of the functions performed by PBAs, utilizing two different forms of measurement as described above.

Moreover, we clustered PBAs into three distinct types, differentiating between business associations (BA), intermediary unions (IU), and liberal professional societies (LPS), which have been identified at an earlier stage of this research (Ivanova 2013). However, the fact that there are at least three different types of PBAs in Russia with varying characteristics with regard to age, size, field of activity, type of membership, etc. helps us to better interpret our findings. For instance, most of the BAs (98\%) and IUs (87\%) in our sample were established after 1991; however, about half of LPSs (47\%) were founded before 1991. BAs represent the real and service sectors of the economy, are relatively young (on average 10 years $^{3}$ ), have a moderate number of paid employees (on average 13 people), combine voluntary (76\%) and obligatory (24\%) membership, and have primarily collective members (78\%). IUs exist to support

3 At the moment when survey took place, that is in 2013. 
business and entrepreneurs, represent rather aged organizations (on average 15 years), employ a sizable paid staff (on average 20 persons), and have exclusively voluntary membership that is predominantly collective (87\%). LPSs unite representatives of culture, healthcare, science and education. They are the oldest type of association (on average 41 years) and demand the least personnel (on average 3 persons). The membership is voluntary only and primarily individual (96\%). Due to varying historical settings in which these organizations were established, there are differences in the way they operate between more dynamic and future oriented BAs, realistic IUs and more cautious traditional LPSs (Ivanova 2013).

For testing differences in function fulfilment between these three different types of PBAs, we applied nonparametric tests (Mann-Whitney for comparing two samples), since the variables in our sample on the relative importance of the service, advocacy, and community building functions are not distributed normally. This method allows us to identify whether significant differences between different types of PBAs appear. Finally, in order to contextualize the findings of the survey with regard to the meaning of the functions, the last part of the analysis is based on the set of criteria derived from the expert interviews in relation to three different types of PBAs.

\section{Results: Functional Orientation by Type of PBA}

Our methods of measuring PBAs' functions allowed us to investigate the multifunctional nature of associations by looking at the composition of functions they perform. Depending on the measurement approach used, we revealed that almost three quarters of PBAs in Russia contribute to all three functions simultaneously. The definite share varies from $72 \%$ (goals) to $87 \%$ (work time). Every fifth PBA (20\% for both scales) contributes solely to two functions simultaneously, with the most frequent combination of advocacy and community building (goals) and advocacy and service delivery (work time). Finally, only a minor number of PBAs, varying from 3\% (work time) to $8 \%$ (goals) specializes in one function only. Compared to findings from a study on the functions performed by nonprofits in Austria and the Czech Republic, Russian PBAs are significantly more inclined to perform all three functions simultaneously, given that only $10 \%$ of NPOs in Austria and $17 \%$ of those in the Czech Republic contribute to all three functions simultaneously, whereas a large number of Austrian NPOs (59\%) and a significant number of Czech NPOs (40\%) are specialized in one function only (Neumayr and Schneider 2008). This difference could be explained by the specific type of NPO represented by associations, 
where multi-facetedness is one of its distinctive features (Edwards and Foley 2001; Zimmer and Freise 2008; Zimmer 2007). Our findings demonstrate that the majority of PBAs in the sample are multi-functional, proving the multi-tasking nature of associations empirically and further confirming applicability of the undertaken theoretical approach in the transitional context.

When looking at the relative importance of PBAs' functions, we found that advocacy is the most important function across all types of PBAs when measured in work hours (see Figure 3). Regarding the particular types of PBAs, our main finding is that BAs and IUs have a rather similar functional specialization; regardless of the measurement scale, the leading role belongs to the advocacy function (see Figures 2 and 3). LPSs deviate in this respect, given that the two measurement approaches deliver different results, and the advocacy function is challenged by the community building function for being the most important.

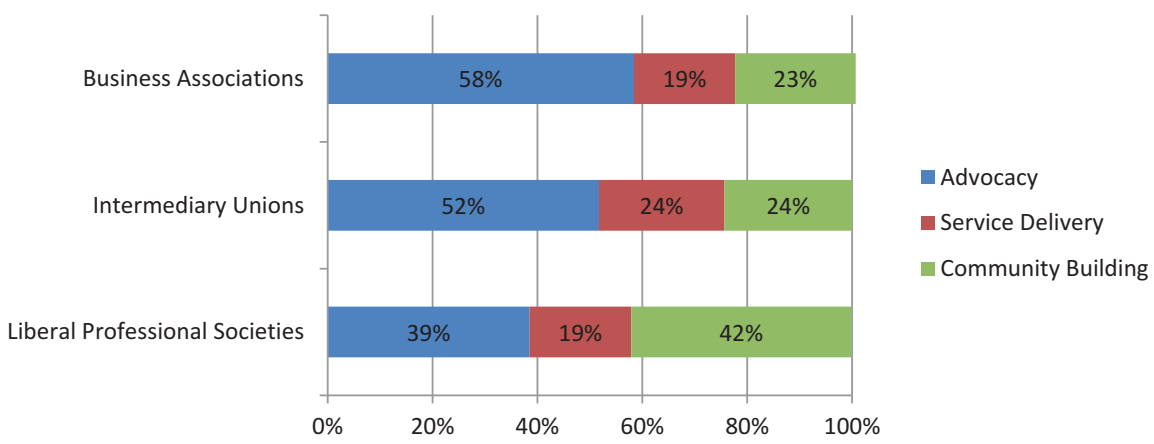

Figure 2: Distribution of relative importance of functions of PBAs by organizational goals, $N=210$. Source: Russian PBA-Survey, 2013, $N=210$.

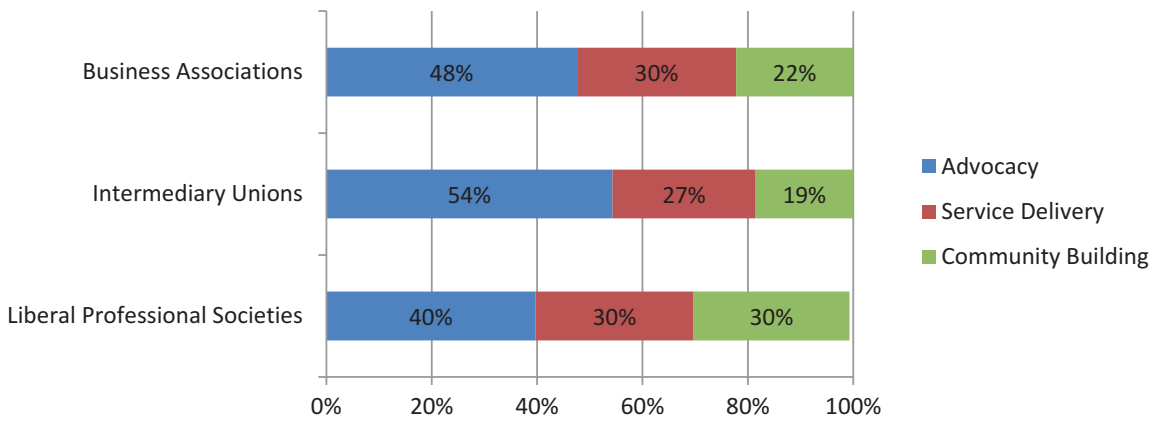

Figure 3: Distribution of relative importance of functions of PBAs by work hours.

Source: Russian PBA-Survey, 2013, $N=210$. 
At the same time the other two functions - service delivery and community building - rank interchangeably as of second or third importance, but taken together they are as important as advocacy.

When we apply the first measurement approach (Figure 2), based on perception of organizational goals, for both BAs and IUs advocacy composes the most important function, community building the second and service delivery the least important. A somewhat different distribution of functions' priority is established for the LPSs, where the community building function (42\%) is just as important as advocacy (39\%), substantially diminishing service delivery (19\%). When we compare the relative importance of the advocacy function for BAs and IUs no significant differences appear $(p=0.130)$, but advocacy is more relevant for BAs (average of $58 \%$ vs. $39 \%$ ) than for LPS ( $p=0.001$ ), as well as for IUs (average of $52 \%$ compared to $39 \%)$ than for LPSs $(p=0.002)$. The community building function is significantly more important for LPSs (average $42 \%$ vs. $23 \%)$ than for BAs $(p<0.001)$, whereas no statistically significant links were found for the importance of this function between BAs and IUs $(p=0.391)$, as well as between IUs and LPSs $(p=0.103)$. Concerning the service delivery function, no significant differences appear between the three types of PBAs.

The findings on the relative importance of PBAs' functions based on the measurement in work hours (Figure 3) almost replicate our findings from the approach based on goals. We observed even less differences between the three types of PBAs, as well as in the allocation of priorities between the functions. For all types of PBAs, the most important function is advocacy both relatively and absolutely. However, advocacy is significantly more important for IUs (average of $54 \%$ compared to $40 \%$ ) than for LPSs ( $p<0.001)$ and slightly less significantly relevant for BAs (average of $48 \%$ vs. $40 \%$ ) than for LPS ( $p=0.047$ ). The remaining two functions occupy approximately half of work time across the different types of PBAs, which corresponds to the same pattern identified by measurement in goals. Thus, the similarities between all three groups of PBAs are apparent. Moreover, service appears as the second most important function across all types of PBAs, leaving behind community building as a third priority. These results come into contradiction with the findings from the measurement in goals, as the importance of community building was rated higher than that of service delivery across all three groups of PBAs. The service delivery function accounts for almost one third of work hours across all three types of PBAs. At the same time, in fulfilling this function no significant differences appear between the three types of PBAs. The third function, community building, is slightly less important when this type of measurement is applied. All endeavours towards community building are significantly more important for LPSs than for BAs ( $p=0.015)$, as they devote $30 \%$ of work hours to community building activities, while BAs devote only $22 \%$. The same is true for 
the LPSs in comparison with IUs $(p=0.003)$, since the latter assigns slightly less ( $27 \%$ ) hours worked to the community building function. At the same time, no statistically significant links were found for the importance of this function between BAs and IUs $(p=0.349)$.

If findings on the relative importance of PBAs' functions appear to be fairly consistent for the advocacy function as the most important function for this type of nonprofits, the same does not apply for the service delivery and community building functions. The inconsistencies in the order of importance of service and community building could be explained by the distinctive measurement approaches applied. Community building is rated somewhat more important when measured by PBAs' goals and not in work hours. Such a difference could be attributed to the character of the community building function, since in transitional societies bridging trust and horizontal communications take longer time to develop (Spencer 2011). Therefore, even though PBAs give a high priority to community building, the amount of time they allocate for its implementation on a daily basis is somewhat lower. Another interpretation for the higher importance of community building, when measured in goals, lays in the fact that mostly top executives took part in the survey. In their view, advocacy and community building are strategically more important than the tactical routine of service delivery. At the same time, the share of time allocated to the fulfillment of service delivery is higher in comparison with community building across all types of PBAs.

Our data clearly show that PBAs represent the advocacy-dominated type of NPO that one would usually expect for the institutionally stable Western societies. This finding might appear counter intuitive with respect to transitional societies, where institutional settings are unstable and societal relations not so well structured. Thus, often overlooked contribution of domestic associations to market economy (by means of the service delivery function), democracy (by means of the advocacy function) and healthy civil society (by means of the community building function) is of crucial importance for countries in transition.

\section{Tactics and Strategies of Fulfilling Advocacy, Community Building and Service Delivery in a Transitional Context}

Apart from examining the relative importance of the three major functions for different types of PBAs, the subsequent section aims to provide a better 
understanding of the ways in which these functions are implemented in the transitional context. The results of the exploratory qualitative analysis showed that by and large, Russian PBAs demonstrate multi-functionality and fulfil all three major societal functions simultaneously, similar to their counterparts in the West but in a more subtle way (Ivanova 2015).

\section{Advocacy for the Informal and Formal Influence}

As already mentioned, advocacy is found to be the most important societal function performed by the examined PBAs in Russia (Ivanova 2013). Even though advocacy can be fulfilled in multiple ways, the experts interviewed referred to two different ways of performing advocacy. First, as a deliberate representation of the interests of collective agencies directed towards the state (policy advocacy) and second as awareness-raising activities through the media addressing society at large (public advocacy). Examples of policy advocacy are found in such statements of experts as 'associations are created first of all to lobby interests' (Interview, former member of BA), and 'our association aims to improve the legal environment' (Interview, CEO of BA). With respect to public advocacy, an expert emphasised 'I am a member of an association, but as an expert community it seeks ways to participate in setting the public agenda... To put it briefly, it [website] is one of the ways to create a platform for promotion of our expertise to a wider community' (Interview, member of LPS). In the expert interviews, media was mentioned less often as a public advocacy tool than relations with the government. Experts brought up only a few examples of public advocacy through the use of media. This might be due to the fact that traditional media (e.g., television, radio, newspapers) are by and large controlled by the state in Russia. At the same time, a certain credit is given to media as an important stakeholder for associations. One of the experts stressed its role: 'In a confectionary association there were talks that one needs to save the domestic producer..., when there was a problem with the Ukrainian competitors, ..., there were attempts to solve it through the media' (Interview, former member of BA).

The interviewed experts pointed out two strategies for successful advocacy in Russia. For the policy advocacy efforts, informal close ties with public officials within a mutually shared atmosphere of privacy are of crucial importance. In contrast, a pattern of maximal openness and transparency in articulating their position is essential for the successful awareness-raising activities within public policy efforts. The analysis of our interview data reveals that Russian PBAs utilise both forms of advocacy, and exercise influence by directly 
addressing responsible government officials or indirectly their counterparts in the elites and wider societal circles. In fulfilling their political mission through varied expressive activities, the two most important roles of PBAs' members highlighted by the experts are as follows: funders that help in fundraising activities, and opinion makers that generate ideas and promote agendas.

Findings from the confirmatory quantitative study also proved that both types of advocacy are implemented by Russian PBAs. However, statistically significant differences between different types of PBAs and forms of advocacy are only found for policy advocacy between LPSs and IUs $(p<0.001)$ and LPSs and BAs $(p<0.001)$ and for public advocacy between LPSs and BAs $(p=0.012)$. In other words, as seen from Table 3, depending on the type of PBAs, for BAs and IUs activities contributing to policy advocacy are more important in terms of allocated labour than for LPSs. But for LPSs in comparison to BAs the situation is exactly the opposite; they put more emphasis on being heard as a public voice. Thus, both BAs and IUs are more active in influencing policy makers through direct interaction, whereas LPSs are more engaged in mobilising public opinion by indirect interaction. Such a difference in the practice of advocacy can be partially explained by the fact that BAs and IUs have more paid staff than LPSs, which enables them to engage with the policy makers on a regular basis on various occasions that involve professional expertise. While LPS have significantly fewer resources available, limiting their direct access to policy makers and leaving them with the option to influence them indirectly through less resource intensive PR activities. Another reason for the minor importance of policy advocacy for LPSs can be attributed to the character of relations between the government and this type of associations. Since LPSs are by far the oldest group of the examined PBAs, it is hard for them to overcome traditional dependency on state support in the field of social and cultural services. On the contrary, business and entrepreneurship oriented BAs and IUs, which emerged in parallel with the modern Russian state, were more capable of building constructive government relations as their fields became more structured. The most vivid example are peak associations (IUs) for large, medium and small

Table 3: Relative importance of the policy advocacy and public advocacy for different types of PBAs by work hours.

\begin{tabular}{lrr}
\hline Types of PBAs & Policy advocacy (\%) & Public advocacy (\%) \\
\hline Liberal professional societies & 15 & 25 \\
Intermediary unions & 34 & 20 \\
Business associations & 30 & 18 \\
\hline
\end{tabular}

Source: Russian PBA-Survey, 2013, $N=210$. 
business, whose existence was strongly supported by the state (Markus 2007). Thus, at least on a pro-forma basis, as has been emphasized by the experts, the leading Russian PBAs have been acknowledged as partners of the state in the public policy debate.

In our confirmatory study, we also examined the character of PBAs' relations with the existing societal structures and discovered striking similarities across all three types of associations regarding the evaluation of their contribution to societal development (Table 4). Over $85 \%$ of the examined PBAs (see Table 4, section A) agree that their activities support existing structures in society. Such overwhelming support of associations towards the state, as a dominant player in the intersectoral relations, is indicative of PBAs' societal embeddedness and their close collaborative relations with the policy makers. The fact that over $70 \%$ of the examined PBAs (see Table 4, section B) disagree that their efforts undermine existing societal structures also proves that associations represent a close proponent of the state. Perhaps such attitudes can be explained by remaining self-censorship practices among the leaders of PBAs, who participated in the survey, since most of them were brought up and socialized in the closed society of the USSR. When it comes to identifying themselves as an alternative to the existing societal structures, the picture of PBAs' activities is somewhat different. Opinions are divided on this issue. For instance, most supporters of an alternative status are found among IUs (42\%), but roughly the same $(40 \%)$ share of IUs disagrees with being seen as an

Table 4: Character of PBAs' organizational activities in relation to existing societal structures.

\begin{tabular}{|c|c|c|c|c|c|}
\hline $\begin{array}{l}\text { Character of PBAs' organizational } \\
\text { activities }\end{array}$ & $\begin{array}{r}\text { Strongly } \\
\text { agree }\end{array}$ & Agree & Disagree & $\begin{array}{l}\text { Strongly } \\
\text { disagree }\end{array}$ & $\begin{array}{r}\text { Do not } \\
\text { know }\end{array}$ \\
\hline
\end{tabular}

A. Supporting existing societal structures

$\begin{array}{lllllr}\text { Liberal professional societies (\%) } & 30 & 55 & 4 & 0 & 11 \\ \text { Intermediary unions (\%) } & 49 & 46 & 0 & 0 & 5 \\ \text { Business associations (\%) } & 36 & 51 & 1 & 1 & 11 \\ \text { B. Undermining existing societal structures } & & & & & \\ \text { Liberal professional societies (\%) } & 0 & 1 & 23 & 50 & 26 \\ \text { Intermediary unions (\%) } & 0 & 3 & 13 & 49 & 13 \\ \text { Business associations (\%) } & 1 & 2 & 24 & 49 \\ \text { C. Providing alternative societal structures } & & & & 25 & 31 \\ \text { Liberal professional societies (\%) } & 9 & 23 & 12 & 24 & 18 \\ \text { Intermediary unions (\%) } & 8 & 34 & 16 & 24 & 24 \\ \text { Business associations (\%) } & 5 & 23 & 22 & & \\ \end{array}$

Source: Russian PBA-Survey, 2013, $N=210$. 
alternative structure (see Table 4, section C). Thus, it seems that representatives of PBAs managed to establish constructive working relationships with their counterparts in the government to lead a meaningful dialogue under the leading role of the government.

Another example of associations as an institutional infrastructure represent major peak associations. Since 1999, they have functioned as employers' unions and were involved in constant political dialog with the federal government and trade unions on the basis of the Trilateral Commission on the Regulation of Social and Labour Relations. The cooperation between the state and PBAs has been intensified through the emerging system of public advisory boards at multiple governmental levels (Yakovlev et al. 2010, 63). However, the experts that took part in our interviews were far from giving optimistic evaluations to this innovation in public policy. One critically-minded expert with a skeptical attitude towards these institutions stated: 'these public advisory boards died before being born... formally they are established, but they don't get together and don't work... yes, we are members there, but rather in order to have contacts with the government officials' (Interview, CEO of BA). A less critical evaluation of boards' activities reads as follows: 'Such boards are working in principle, but it depends on the ministries, how much they are ready to listen' (Interview, CEO of GR Agency). Thus, despite having old and new institutionalized formal structures for cross-sectoral cooperation, there is still a heavy reliance on individual relationships between PBAs and governmental bodies. Our analysis of the expert interviews revealed that PBAs use every opportunity to participate in shaping public policy by strengthening their informal ties with representatives of the executive branch of Russian government. All in all, such emerging institutions for cross-sectoral cooperation show that the government acknowledges the political role of PBAs, at least for IUs and BAs, who take a more active part in shaping public policy than LPSs.

\section{Community Building for Horizontal Bonding and Networking}

Similar to the advocacy function, different perceptions of the community building function appeared in our expert interviews. Two of the most common interpretations refer to being a unifying agency for existing and new members of PBAs and to being a point of coordination between different organizational stakeholders. Interview data suggests that the logic of interaction is the best way to describe how community building activities are performed. This function is 
implemented in multiple ways. Interviewed experts named such simple forms of community building, as regular networking events aimed at contributing to a sense of community. The more advanced forms mentioned in the interviews refer to the formation of a field specific code of ethics, as well as to the establishment of the formal accreditation processes, creation of professional standards, and the certification of actors within certain professional or business fields.

We know from the theory that activities within the community building function result in enhanced trust, which is expressed through formal social capital aimed at bridging different groups in society and informal social capital that bonds together persons holding the same views (Putnam 2000). In our interviews there were plenty of examples for community building activities which enhance bonding social capital. For instance, an expert underlined that '... here we are talking about creating cooperation that is about creating professional networks... We have over 1,000 researchers, who are interested in political science '(Interview, member of LPS). This example shows that PBAs facilitate collective action by bringing like-minded people together. Examples of the bridging function that community building activities perform in order to link different groups in society were mentioned considerably less frequently. One of the examples from our interviews that illustrates this function is 'All these conferences, fora, round tables, including those that we conduct on certain topics, allow the scientific community, political quarters, and representatives of the business community to meet and come up with certain positions and recommendations' (Interview, member of IU). The fact that informal bonding types of community building practices prevail over more formal bridging practices among Russian PBAs is supported by the findings of an ethnographic research of nonprofits, which pointed out traditionally high levels of informal social capital in Russia (Spencer 2011). Most researchers agree that deficient levels of formal social capital hinders democratization and civil society development, remaining a common problem across transitional countries, as was also revealed in the case of Czech NPOs (Neumayr et al. 2009).

Another specific feature of Russia's context mentioned by the interviewed experts in relation to the community building function is a traditional approach taken by the state to structure its relations with civil society in a top-down manner through major peak associations. Such an approach prevents horizontal cooperation across different groups in society, which takes more time to develop. Perhaps this is another typical feature of the post-communist transitional countries whose associational infrastructure is not as established and trusted by the government as those in developed countries. Another factor that restricts collaboration between PBAs is competition that some of them encounter. For example, an expert recalled that 'Competition is moderate, but it exists. 
As a rule, it exists between associations of related or partially overlapping market sectors... Sometimes they cooperate, sometimes they compete for members or influence over the relevant government body' (Interview, CEO of BA). Overall, there is a great potential for closer cooperation between different PBAs as they mature and gain public weight.

\section{Service Delivery for Attracting and Keeping Members}

As already mentioned, importance of the service delivery function is substantially inferior to the advocacy function and challenges the community building function for being the second most important type of PBAs' activities. Experts considered service delivery as addressed to members, whose roles are perceived as primarily that of clients or information inquirers. The most often mentioned ways of service provision in associations included the provision of members with relevant statistical data, analytical reports and specialized knowledge. The critical resources for the efficient delivery of high quality services are bureaucratically organized and professionally managed structures of PBAs. According to interview data, the ability of PBAs' paid staff to coordinate dialog between members, to raise funds, and to attract volunteers serves as a prerequisite for the successful implementation of this function. A few experts mentioned commercialization as an outcome of service activities, which is necessary for the sustainable funding of PBAs but might also cause a shift from their multifaceted mission (Shaw and Allen 2009).

Examples of the service delivery function from our interviews show that PBAs tend to offer resource intensive services to their members. As one of the experts mentioned: 'The association accumulates a lot of necessary and useful information by virtue of its nature' (Interview, member of a BA). One more example of the service delivery function was pointed out by another expert: 'There is an interesting mechanism of holding annual fairs. For instance, 'Rosagromash'. We worked with this association. They carry out an annual forum-fair, where all producers come. They rent Crocus-City, earn 1 million dollars on that and the association is funded for the year ahead' (Interview, CEO of the GR Agency). All in all, PBAs show involvement in the service delivery function, since it is vital for their existence as a membership based organization. Members who do not see a personal benefit from PBAs' services may withdraw their membership at any time. 


\section{Conclusion}

We started our study by pointing out that associations are very complex phenomenon. To date associations have received scant attention from non-profit researchers in the developed and transitional contexts. We selected PBAs as the subject of our investigation, since they form an important part of the nonprofit sector in Russia, by the share of people employed, this type of NPOs is the fourth largest employer in the sector. We applied a theoretical framework of NPOs' functions with reference to the organizational level and investigated the functions performed by PBAs in Russia. In our mixed-methods study we tried to conceptually and empirically extend prior research which has focused on nonprofits' functions primarily in a developed context, to a transitional context. Examining the major functions of PBAs through the lenses of their contribution to three subsystems of society - political, communitarian and economic - allowed us to confirm the multifaceted nature of associations operating in a transitional context. Through an analysis of organizational data, we were able to describe PBAs' activities and the relative importance of the three functions that different types of PBAs fulfill.

As our organizational data clearly show, all types of PBAs are multifunctional, contributing simultaneously not only to the political system, but also to the market and society at large. Moreover, this multi-functional character of associations appeared considerably more distinct in case of Russian PBAs in comparison to NPOs from Austria and the Czech Republic (Neumayr et al. 2009). Our analysis showed that advocacy is the most important function across all types of PBAs, when the distribution of work time is taken into consideration. The remaining service delivery and community building functions occupy the other half of work hours for all types of PBAs. Moreover, we found that LPSs allocate significantly more labor hours to the community building function than BAs and IUs. For PBAs in Russia, community building activities are more relevant in the form of informal bonding activities, rather than formal bridging activities. The repertoire of PBAs' ways to carry out advocacy activities that PBAs use consists of both direct and indirect efforts. In their contribution to democracy, BAs and IUs prefer direct policy advocacy, while LPSs engage more in indirect public advocacy. Moreover, LPSs are the smallest organizations in terms of size, significantly conceding to more human resources intensive IUs and BAs. Against this background, it appears obvious that younger and well-resourced BAs and IUs focus their efforts more on the policy advocacy that requires specialized expertise, while older and poorer LPSs are more involved in public advocacy and community building, relying on the well-established connections within their field. 
The findings enhance our understanding of the multifunctional nature of professional and business associations and their contribution to the institutional infrastructure in a country in transition. We are aware that crosssectional data gave us only a snap-shot picture of associational activities in Russia in 2011-2013. However, by triangulating quantitative findings with qualitative data we were able to provide a better interpretation of the current and past developments within the Russian associational sphere. Nevertheless, we have to be cautious when trying to generalize our findings and apply them to different cultural and political settings. The limitations of the present study suggest directions for further research. Definitely, there is a need for qualitative and historiographic investigations into the successful modes of cooperation between non-profit organizations and the state in order to scale up the lessons learned from PBAs to non-profit organizations in general in creating an environment that stimulates market economy, democracy development and social cohesion.

Overall, this study showed that professional and business associations in the transitional context serve as an important institutional infrastructure that supports the development of civil society, democracy and capitalism. Most of the literature on Russia's nonprofit sector overlooks this contribution of associations as a fundamental building block of market, political and societal life. This is especially disappointing, given the very sceptical and rarely challenged assumptions about Russia's civil society a priori adopted by Western nonprofit researchers (Crotty 2014). A rare but powerful exception is a call to be more balanced in assessing civil society development in Russia (Javeline and Lindemann-Komarova 2010). In this article we tried to adopt such a balanced approach, by examining activities of domestic associations, which emerged in an evolutionary way and were not imposed from abroad. In doing so, we illustrated their potential for a sustainable societal development in the transitional context. We believe that by drawing attention to the supporting structures of civil society, the experience of fostering the institutional infrastructure from Russia could serve as an example for other countries in transition.

Acknowledgments: This paper has been presented at the $11^{\text {th }}$ ISTR International Conference in Muenster, Germany. Authors are grateful to reviewers and discussants for their comments and suggestions, which helped us to significantly revise and improve the paper. Special acknowledgement goes to three reviewers of this journal for helpful suggestions to further improve the paper. 


\section{References}

Anheier, H. K. 2005. Nonprofit Organizations: Theory, Management, Policy. London: Routledge. Crotty, Jo. 2014. "Corporate Social Responsibility in the Russian Federation: A Contextualized Approach.” Business \& Society. doi: 10.1177/0007650314561965.

Duvanova, D. S. 2011. "Firm Lobbying Versus Sectoral Organization: The Analysis of Business-State Relations in Post-Communist Russia." Post-Soviet Affairs 27 (4): 387-409.

Edwards, B., and M. W. Foley. 2001. "Civil Society and Social Capital: A Primer." In Beyond Tocqueville: Civil Society and the Social Capital Debate in Comparative Perspective, edited by B. Edwards, M. W.. Foley and M. Diani. Hannover: University Press of New England.

Frumkin, P. 2005. On Being Nonprofit: A Conceptual and Policy Primer. Cambridge, MA: Harvard University Press.

Grønbjerg, K. A., H. K. Liu, and T. H. Pollak. 2010. “Incorporated but Not IRS-Registered: Exploring the (Dark) Grey Fringes of the Nonprofit Universe." Nonprofit and Voluntary Sector Quarterly 39 (5):925-45.

Haynes, W., and B. Gazley. 2011. "Professional Associations and Public Administration: Making a Difference?" In The State of Public Administration: Issues, Challenges, and Opportunities, edited by D. C. Menzel and H. L. White, 54-69. Armonk: M.E. Sharpe.

Ivanova, E. 2013. "Russian Professional Associations: Sleeping Beauties, Guardians of Stability or Facilitators of Societal Development? (Rossiyskie Professionalnye Ob’yedineniya: Statisty, Strazhi Stabilnosti Ili Provodniki Obshchestvennogo Razvitiya)." Voprosy Ekonomiki 11:112-28.

Ivanova, E. 2015. "The Role of Professional and Business Associations in Development of Civil Society in Russia." Doctoral dissertation, Management, WU Vienna University of Economics and Business, Vienna, Austria.

Javeline, D., and S. Lindemann-Komarova. 2010. "A Balanced Assessment of Russian Civil Society." Journal of International Affairs 63 (2):171-88.

Knapp, M., E. Robertson, and C. Thomason. 1990. "Public Money, Voluntary Action: Whose Welfare." In The Third Sector: Comparative Studies of Nonprofit Organizations, edited by H. K. Anheier and W. Seibel. 183-218. Berlin: Walter de Gruyter.

Krippendorff, K. 2004. Content Analysis: An Introduction to Its Methodology, 2nd ed. Thousand Oaks: Sage.

Land, K. C. 2001. "Social Indicators for Assessing the Impact of the Independent, Not-for-Profit Sector of Society." In Measuring the Impact of the Nonprofit Sector, edited by P. Flynn and V. A.. Hodkinson, 59-80. New York: Kluwer Academic/Plenum Publishers.

Ljubownikow, S. 2011. An Examination of the Management of Russian Civil Society. Birmingham: Aston University.

Luhmann, N. 1984. Soziale Systeme. Grundriß Einer Allgemeinen Theorie. Frankfurt: Suhrkamp. Markus, S. 2007. "Capitalists of All Russia, Unite! Business Mobilization Under Debilitated Dirigisme.” Polity 39 (3):277-304.

Mayring, P. 2010. Qualitative Inhaltsanalyse: Grundlagen Und Techniken, 11th ed. Basel: Beltz Verlag.

Mersiyanova, I. V. 2010. Russian third sector: key characteristics and operational environment (Rossiyskiy tretiy sektor: osnovnye kharakteristiki i usloviya deyatelnosti). In Russian Third Sector: Key Characteristics and Operational Environment. 26.01. Moscow. 
Mersiyanova, I. V., A. F. Cheshkova, and I. I. Krasnopolskaya. 2011. Self-Organization and Problems of Professional Societies' Formation in Russia (Samoorganizatsiya I Problemy Formirovaniya Professionalnyh Soobshchestv). In Edited by I.V. Mersiyanova. Vol. VII, Monitoring of Civil Society. Moscow: National Research University - Higher School of Economics.

Minkoff, D. C. 2002. "The Emergence of Hybrid Organizational Forms: Combining Identity-Based Service Provision and Political Action." Nonprofit and Voluntary Sector Quarterly 31 (3):377-401. doi: 10.1177/0899764002313004.

Moskovskaya, A., O. Oberemko, V. Silaeva, I. Popova, I. Nazarova, O. Peshkova, and M. Chernysheva. 2013. Development of Professional Associations in Russia. Moscow: Higher School of Economics.

Neumayr, M. 2010. Resource Dependence: Der Einfluss Öffentlicher Finanzierungsformen Auf Die Funktionen Von Nonprofit Organisationen in Österreich. Vienna: Management, WU.

Neumayr, M., and M. Meyer. 2010. "In Search of Civicness: An Empirical Investigation of Service Delivery, Public Advocacy, and Community Building by Civil Society Organizations." In Civicness in the Governance and Delivery of Social Services, edited by T. Brandsen, P. Dekker and A. Evers, 201-26. Baden-Baden: Nomos.

Neumayr, M., M. Meyer, M. Pospíšil, U. Schneider, and I. Malý. 2009. "The Role of Civil Society Organizations in Different Nonprofit Regimes: Evidence From Austria and the Czech Republic." In Civil Society in Comparative Perspective, edited by B. Enjolras and K. Henrik Sivesind, 167-96. Bingley: Emerald Group Publishing Limited.

Neumayr, M., and U. Schneider. 2008. “Nonprofit Organisationen - Mehr Als Nur Dienstleister? Empirische Befunde Zu Den Funktionen Von Nonprofit Organisationen in Österreich Und Der Tschechischen Republik." In Steuerung Und Kontrolle in Nonprofit-Organisationen, edited by R. Schauer, B. Helmig, R. Purtschert and D. Witt, 397-418. Wiesbaden: DUVGabler.

Paffenholz, T., and C. Spurk. 2006. Civil Society, Civic Engagement, and Peacebuilding. Social Development Papers: Conflict Prevention and Reconstruction, No. 36. Washington, DC: Social Development Department of The World Bank.

Prewitt, K. 1999. "The Importance of Foundations in an Open Society." In The Future of Foundations in an Open Society, edited by M. Strübin and P. Walkenhorst, 17-29. Guetersloh: Bertelsmann Foundation Publishers.

Putnam, R. D. 1993. Making Democracy Work. Civic Traditions in Modern Italy, Princeton Paperbacks: Political Science. Princeton: Princeton University Press.

Putnam, R. D. 2000. Bowling Alone: The Collapse and Revival of American Democracy. New York: Simon and Shuchter.

Pyle, W. 2006. "Collective Action and Post-Communist Enterprise: The Economic Logic of Russia's Business Associations.” Europe-Asia Studies 58 (4):491-521.

Salamon, L. M., L. C. Hems, and K. Chinnock. 2000. The Nonprofit Sector: For What and for Whom? Working Papers of the Johns Hopkins Comparative Nonprofit Sector Project, No. 37. Baltimore, MD: Johns Hopkins Center for Civil Society Studies.

Salamon, L. M., W. S. Sokolowski, and H. K. Anheier. 2000. Social Origins of Civil Society: An Overview. Baltimore: The Johns Hopkins Comparative Nonprofit Sector Project.

Salamon, L. M., W. S. Sokolowski, M. A. Haddock, and H. S. Tice. 2013. The State of Global Civil Society and Volunteering: Latests Findings From the Implementation of the UN Handbook. Working Paper No. 49. Baltimore: Johns Hopkins Center for Civil Society Studies. 
Shaw, S., and J. B. Allen. 2009. "To Be a Business and to Keep Our Humanity." Nonprofit Management and Leadership 20 (1):83-96.

Spencer, S. B. 2011. "Culture as Structure in Emerging Civic Organizations in Russia." Nonprofit and Voluntary Sector Quarterly 40 (6):1073-91.

Then, V., and K. Kehl. 2011. Social Investment: A Conceptual Outline 40th ARNOVA Annual Conference.

Tschirhart, M.. 2006. "Nonprofit Membership Associations." In The Nonprofit Sector: A Research Handbook, edited by W. W. Powell and R. Steinberg, 523-41. New Haven: Yale University Press.

Wagner, A. 2012. “'Third Sector' and/or 'Civil Society’: A Critical Discourse About Scholarship Relating to Intermediate Organisations." Voluntary Sector Review No 3 (3):299-328.

Warren, M. E. 2001. Democracy and Association. Princeton: Princeton University Press.

Yakovlev, A. A., A. Yu. Zudin, V. V. Golikova, A. V. Govorun, E. V. Astafyeva, and G. A. Garifullina. 2010. Business Associations in Russia: Internal Structure, Evolution of Relations with the State, Role in Modernization of the Economy (Biznes-Assotsiatsii V Rossii: Vnutrennyaya Struktura, Evolyutsiya Otnoshenij S Gosudarstvom, Rol' V Modernizatsii Ekonomiki). Edited by Andrey A. Yakovlev. Moscow: Moscow Public Science Foundation.

Zimmer, A. 2007. Vereine-Zivilgesellschaft Konkret. Wiesbaden: VS Verlag für Sozialwissenschaften.

Zimmer, A., and M. Freise. 2008. "Bringing Society Back in: Civil Society, Social Capital, and Third Sector." In Civil Society and Governance in Europe, edited by W. A.. Maloney and J. W. Van Denth, 19-45. Northhampton: Edward Elgar Publishing Ltd. 